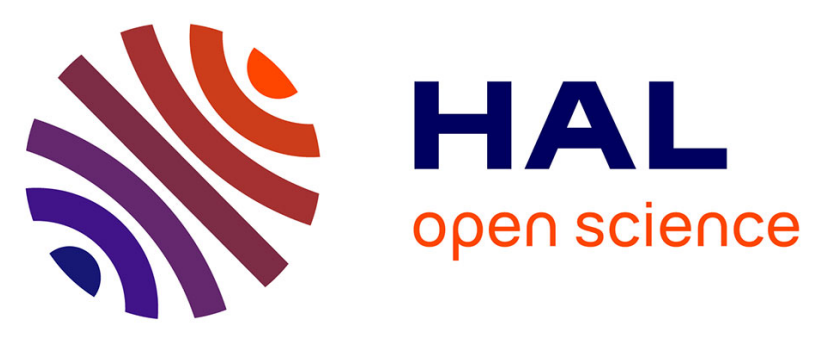

\title{
High prevalence of chronic kidney disease in La Réunion island and its association with the metabolic syndrome in the non-diabetic population: La Réunion Diabetes (REDIA) Study.
}

Béatrice Stengel, Isabelle Jaussent, José Guiserix, Bruno Bourgeon, Laure Papoz, Francois Favier, Redia Study Group

\section{To cite this version:}

Béatrice Stengel, Isabelle Jaussent, José Guiserix, Bruno Bourgeon, Laure Papoz, et al.. High prevalence of chronic kidney disease in La Réunion island and its association with the metabolic syndrome in the non-diabetic population: La Réunion Diabetes (REDIA) Study.: Chronic kidney disease and metabolic syndrome. Diabetes \& Metabolism, 2007, 33 (6), pp.444-452. 10.1016/j.diabet.2007.10.002 . inserm-00169536

\section{HAL Id: inserm-00169536 https://www.hal.inserm.fr/inserm-00169536}

Submitted on 19 Nov 2007

HAL is a multi-disciplinary open access archive for the deposit and dissemination of scientific research documents, whether they are published or not. The documents may come from teaching and research institutions in France or abroad, or from public or private research centers.
L'archive ouverte pluridisciplinaire HAL, est destinée au dépôt et à la diffusion de documents scientifiques de niveau recherche, publiés ou non, émanant des établissements d'enseignement et de recherche français ou étrangers, des laboratoires publics ou privés. 


\section{HAL author manuscript}

High prevalence of chronic kidney disease in the Reunion Island: Association with the metabolic syndrome in the nondiabetic population. The REunion-DIAbetes Study.

\section{B Stengel ${ }^{1,2}$ I Jaussent, ${ }^{3,4}$ J Guiserix, ${ }^{5}$ B Bourgeon, ${ }^{6}$ L Papoz, ${ }^{7}$ F Favier, ${ }^{8}$}

The REDIA Study Group ${ }^{9}$

${ }^{1}$ INSERM, Unité 780, Villejuif, F-94807 France

${ }^{2}$ Université Paris-Sud, Faculté de Médecine, IFR69, Villejuif, France

${ }^{3}$ Inserm, U888, Montpellier, F-34493 France

${ }^{4}$ Université Montpellier1, Montpellier, F-34006 France

${ }^{5}$ Service de Néphrologie, Centre Hospitalier Sud Réunion, Saint Pierre, Ile de la Réunion

${ }^{6}$ Service de Néphrologie, Centre Hospitalier Felix Guyon, Saint Denis, Ile de la Réunion

${ }^{7}$ INSERM, Unité 500, Montpellier, F-34000 France

${ }^{8}$ INSERM, Centre d'Investigation Clinique et d'épidémiologie clinique, Centre Hospitalier Sud Réunion, Saint Pierre, Ile de la Réunion

${ }^{9}$ REDIA Study Group - Coordination, Inserm Montpellier : Dr L.Papoz (principal investigator), A. Sanchez, B. Lecointre, I. Jaussent. Field survey, Ile de la Réunion: Dr F. Favier (local coordinator), Dr F. Martinet, Dr A. Brissot, T. Dijoux, M. Damour, MJ. Andrieu, S. Rivière, J. Mani, N. Naty; Centre Hospitalier Sud Réunion, Saint Pierre : Dr JC. Schwager, Dr N. Le Moullec, Dr J. Guiserix, Dr A. Clabé ; Centre Hospitalier Felix Guyon, Saint Denis, Ile de la Réunion: Dr MC. Boyer, Dr X. Debussche, Dr B. Bourgeon, Dr H. Caillens.

Short title: Chronic kidney disease and metabolic syndrome

\section{Corresponding author}

Bénédicte Stengel, MD, PhD

INSERM U780

16 , avenue $P$. Vaillant-Couturier

94807 Villejuif cedex, France

Phone: 33145595039

Fax: 33145595152

e-mail stengel@vjf.inserm.fr 


\begin{abstract}
Aim: To estimate the prevalence of chronic kidney disease (CKD) in the Reunion Island and investigate the link with the metabolic syndrome in the non-diabetic population.

Methods: The REunion DIAbetes Study included a random sample of 3,600 adults aged 30 to 69 years. Clinical proteinuria ( $>200 \mathrm{mg} / \mathrm{g}$ creatinine), albuminuria ( $\geq 30$ $\mathrm{mg} / \mathrm{g}$ ) and estimated glomerular filtration rate (eGFR) were studied in 920 participants, 411 of whom with diabetes and 509 without it. Their relations with the metabolic syndrome (defined by the US National Cholesterol Education Program Adult Treatment Panel III guidelines) were analysed among those without diabetes.

Results: Age-, gender-, and diabetes-standardised prevalence of CKD stage 1 or 2 (proteinuria or albuminuria with $\mathrm{eGFR} \geq 60 \mathrm{ml} / \mathrm{mn} / 1.73 \mathrm{~m}^{2}$ ) was $13.8 \%$ and for CKD stage 3 or more $($ eGFR $<60) \quad 10.7 \%$. The adjusted odds ratios $(\mathrm{OR})$ for proteinuria increased with the number of metabolic syndrome traits: 1.5 (95\% confidence interval, 0.4 to 5.2) in non-diabetic participants with one trait compared with those with no trait, 2.0 ( 0.6 to 6.6 ) for two traits, and 4.1 (1.3 to 12.8) for three or more; corresponding ORs for eGFR<60 were 1.9 ( 0.8 to 4.5$), 0.9$ (0.4 to 2.4 ), and 2.2 (0.9 to 5.1$)$, respectively. The clustering of either high blood pressure and triglyceride levels or high triglycerides and plasma glucose or the three of them conferred the strongest associations with both clinical proteinuria and low eGFR.
\end{abstract}

Conclusion: CKD prevalence is high in the Reunion population. The metabolic syndrome may help targeting early diagnosis of CKD in nondiabetic individuals.

Word count : 252

\title{
Keywords
}

Chronic kidney disease, diabetes, metabolic syndrome, obesity, proteinuria. 
Prévalence élevée de maladie rénale chronique dans l'Ile de la Réunion: association avec le syndrome métabolique dans la population non diabétique. Etude REunion-

DIAbète.

\section{Résumé}

Objectif: Estimer la prévalence de la maladie rénale chronique (MRC) dans l'Ile de la Réunion et étudier le lien avec le syndrome métabolique dans la population non diabétique.

Méthodes: L'étude REDIA porte sur un échantillon représentatif de 3,600 adultes âgés de 30 à 69 ans. Protéinurie clinique ( $>200 \mathrm{mg} / \mathrm{g}$ créatinine), albuminurie ( $\geq 30 \mathrm{mg} / \mathrm{g}$ ) et debit de filtration glomérulaire estimé (eDFG) ont été étudiés chez 920 participants, 411 avec un diabète et 509 sans. Leurs relations avec le syndrome métabolique (défini par le US National Cholesterol Education Program Adult Treatment Panel III guidelines) ont été analysées chez les participants sans diabète.

Résultats: La prévalence standardisée sur l'âge, le sexe et le diabète des stades 1 ou 2 de MRC (protéinurie ou albuminurie avec eDFG $\geq 60 \mathrm{ml} / \mathrm{mn} / 1.73 \mathrm{~m}^{2}$ ) était de $13.8 \%$ et pour les stades 3 ou plus $(e D F G<60)$ de $10.7 \%$. Les odds ratios $(\mathrm{OR})$ ajustés de protéinurie augmentaient avec le nombre de traits du syndrome métabolique: 1,5 (intervalle de confiance à $95 \%, 0,4-5,2$ ) chez les participants sans diabète avec un trait comparés à ceux sans aucun trait, $2,0(0,6-6,6)$ pour deux traits, et $4,1(1,3-12,8)$ pour trois ou plus; les ORs correspondants pour les eDFG $<60$ étaient respectivement 1,9 $(0,8-4,5), 0,9(0,4-2,4)$, and 2,2 (0,9-5,1). Les clusters incluant soit une pression artérielle et des triglycérides élevés, soit des triglycérides et une glycémie à jeun élevés, soit les trois ensemble étaient les plus fortement liés au risque de protéinurie clinique et de bas eDFG.

Conclusion: La prévalence de la MRC est élevée à la Réunion. Chez les personnes non diabétiques, le syndrome métabolique permettrait de cibler le diagnostic précoce des atteintes rénales. 
The Reunion Island population is experiencing a dramatic increase in end-stage renal disease (ESRD).[1] The age- and gender-adjusted prevalence is four times higher in this overseas district than in mainland France with diabetic nephropathy accounting for more than $33 \%$ of the dialysis population.[2] This led to the REDIA (REunion DIAbetes) Study, a large population-based survey of diabetes and its complications, including markers of kidney damage.[3] Few studies have investigated chronic kidney disease (CKD) and its determinants in the general population. [4-8] Such studies are important to identify individuals who might benefit most from early detection and intervention to prevent or delay progression to ESRD and decrease associated cardiovascular risk.

Diabetes and hypertension are well-established renal risk factors.[4,5,7-9] Epidemiological evidence linking obesity to the risk of CKD is growing, despite some inconsistency across studies.[9-15] Abdominal obesity is the clinical hallmark of the metabolic syndrome, which also includes hypertriglyceridaemia, low high-density lipoprotein (HDL) cholesterol, high blood pressure, and high fasting glucose.[16] Its diagnosis has been promoted as a method for identifying individuals at risk for type 2 diabetes and cardiovascular disease, but little information exists about whether it would improve early detection of individuals with CKD in the absence of diabetes.[17-20] Moreover, no study has examined whether some combinations of two or three traits of the metabolic syndrome confer greater risk than others.

We therefore estimated the prevalence of CKD in the Reunion Island population and investigated its relation with the metabolic syndrome both quantitatively and qualitatively among the non-diabetic participants of the REDIA study. 


\section{Methods}

\section{Population and survey design}

The island of Reunion, located in the Indian Ocean close to the eastern coast of Africa, has a multiethnic population of 703,800 inhabitants including white Creoles, half-caste Creoles, Africans, Indians and a minority from Asia and mainland France. Ethnicity, however, is difficult to study in this population because of the high rates of interbreeding over several generations; inhabitants commonly consider themselves to be simply "Réunionnais."

Information about the REDIA population, methods and response rates has already been published.[3] Briefly, 3,600 men and non-pregnant women aged 30 to 69 years were included in 1999 to 2001, from three age- and gender-representative urban and rural areas of Reunion: Saint-Pierre, Le Tampon, and Saint-André. The study design followed a two-step procedure (Figure 1). First, 98 census household clusters were randomly selected, and all eligible persons were interviewed and screened for diabetes at home by a capillary blood sample (response rate, $80.6 \%$ ). Secondly, all participants whose screening was positive, with either a fasting capillary blood glucose $\geq 6.1 \mathrm{mmol} / \mathrm{l}$ or an $\mathrm{HbAlc} \geq 6 \%$, as well as all those with known diabetes, were invited to a morning clinic-based examination; 363 (58\%) and 312 (73\%), respectively, attended. We also examined a random sample of 275 individuals who were screened negative (about 1/10). Overall, 950 persons participated in this second step.

Most participants without known diabetes had a 75-g oral glucose tolerance test, but those whose screening showed a fasting capillary blood glucose $\geq 11.0 \mathrm{mmol} / \mathrm{l} \mathrm{had}$ the test with a standard meal, as did participants with known diabetes. New diabetes cases were diagnosed according to the WHO criteria as reported by Favier et al.[3]

Overall, 426 of these 950 participants were classified as diabetic - $312(73 \%)$ with known diabetes and $114(27 \%)$ with newly diagnosed diabetes, and 522 as not diabetic; the status of 2 was unknown. The study design was approved by the Ethics Committee of St. Eloi Hospital (Montpellier). Informed consent was obtained from all participants. 


\section{Exposure Measurements}

Data collected during the home screening included birth date, gender, place of residence, history of hypertension, body mass index (BMI), and dipstick proteinuria Those obtained during the clinic-based interview included lifestyle factors, use of medications, and diabetic macro- and microvascular complications. Blood pressure was measured at both times and the average of the two systolic and diastolic readings were used. Blood samples were analysed in two laboratories, one for the participants from StPierre and Le Tampon and the other for those from St-André. Inter-laboratory quality control was performed for each indicator measured, and methods were standardised before these analyses. Plasma glucose was measured with the glucose oxydase method and HbAlc with DCA 2000 (Ames, Bayer Diagnostics). Serum HDL cholesterol and triglyceride levels were measured with the enzymatic colorimetric method (Roche).

The metabolic syndrome was defined according to the criteria recommended by the US National Cholesterol Education Program-Adult Treatment Panel III (NCEP-ATP III) guidelines.[16] Elevated blood pressure was defined as an average systolic or diastolic blood pressure $\geq 130 / 85 \mathrm{~mm} \mathrm{Hg}$; abdominal obesity as waist circumference $>$ $102 \mathrm{~cm}$ in men or $88 \mathrm{~cm}$ in women; low HDL cholesterol as $<40 \mathrm{mg} / 1(1.036 \mathrm{mmol} / \mathrm{l})$ in men or $<50 \mathrm{mg} / \mathrm{l}(1.295 \mathrm{mmol} / \mathrm{l})$ in women; high serum triglycerides as $\geq 150 \mathrm{mg} / \mathrm{dl}$ $(1.695 \mathrm{mmol} / \mathrm{l})$; and elevated fasting plasma glucose as $\geq 110 \mathrm{mg} / \mathrm{dl}(6.1 \mathrm{mmol} / \mathrm{l})$. Participants reporting current use of antihypertensive medication were classified as having elevated blood pressure. The metabolic syndrome was defined as the presence of three or more of these traits.

\section{Outcome}

During the clinic-based examination, a morning urine sample was obtained and proteinto-creatinine ratio was analysed with the colorimetric method (Roche) on 942 nonhaematuric specimens. Serum creatinine was analysed by a modified kinetic Jaffé colorimetric method for 925 individuals. Overall, 300 participants with known diabetes, 111 newly diagnosed and 509 without diabetes had both measurements taken. Albuminuria was measured by immunonephelemetry (Dade Behring) in all participants with proteinuria $<100 \mathrm{mg} / \mathrm{l}$, but in only half of those with a higher level. This procedure 
produced 725 measurements, 205 in participants with diabetes (68\%), 75 in those newly diagnosed $(68 \%)$ and 445 in those without diabetes $(87 \%)$. Because albuminuria measures were not available in all participants, we focused on proteinuria throughout the analysis except for CKD prevalence estimate.

We estimated glomerular filtration rates with the simplified Modification of Diet

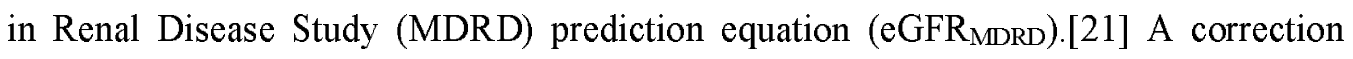
factor for race was applied to participants who reported their ethnicity as African $(n=52)$ or half-caste Creole $(\mathrm{n}=455)$. The CKD staging is from the US National Kidney Foundation [21]: CKD stage 1 (kidney damage and GFR $\geq 90 \mathrm{ml} / \mathrm{mn} / 1.73 \mathrm{~m}^{2}$ ), stage 2 (kidney damage and GFR 60-89), stage 3 (GFR 30 to 59), stage 4 (GFR 15 to 29), stage 5 (GFR $<15$ or renal replacement therapy). To compare with other studies, kidney damage was defined here by the presence of either clinical proteinuria (urinary protein:creatinine ratio $>200 \mathrm{mg} / \mathrm{g}$ ) or albuminuria (albumin:creatinine ratio $\geq 30$ $\mathrm{mg} / \mathrm{g}$ ).[22] In the estimation of CKD stages 1 and 2, individuals with proteinuria $\leq 200$ $\mathrm{mg} / \mathrm{g}$ creatinine and no albuminuria measurement were classified as not having kidney damage. Five individuals on dialysis, all with diabetes, were included in the prevalence study. CKD prevalence was also evaluated based on GFR estimated with the CockcroftGault formula (eGFR $\mathrm{CG}_{\text {), }}$, commonly used in France. We studied the relation of the metabolic syndrome and its traits to two outcomes: clinical proteinuria and chronic renal insufficiency, defined as an $\mathrm{eGFR}_{\mathrm{MDRD}}<60 \mathrm{ml} / \mathrm{mn} / 1.73 \mathrm{~m}^{2}$.

\section{Statistical analyses}

We compared the characteristics of participants and non-participants in the clinic-based examination for each of three groups defined by diabetes status at screening (known diabetes, screened positive or negative). Age-, gender-, and diabetes-standardised prevalences (95\% confidence intervals) of CKD stages in Reunion were calculated by the direct method to take into account response rates by age and gender [3] as well as sampling design by diabetes status. They were weighted by age and gender distribution from the 1999 Reunion census data and gender-specific diabetes prevalence estimated from REDIA (17.7\% in men and $17.3 \%$ in women).[3] CKD stages 4 and 5 were combined to provide more precise estimates of severe renal insufficiency. 
Logistic regression was used to estimate the odds ratios $(95 \%$ confidence intervals) of clinical proteinuria and chronic renal insufficiency associated with the cumulative number of traits of the metabolic syndrome, as well as with each individual trait, and each of ten combinations of two and three traits, adjusted for age, gender, and geographic area. Bonferroni correction for multiple comparisons was applied to recalculate $\mathrm{P}$ values within each group of ten combinations. The effect of further adjustment for smoking and physical activity was tested as well as potential interactions of the metabolic syndrome with gender. Finally, to assess the potential efficacy of the metabolic syndrome as a target for early CKD screening, we estimated the number of subjects $\left(\mathrm{N}_{\mathrm{i}}\right)$ that would have to be screened to detect at least one case with clinical proteinuria for each trait or combination $i$, as follows:

$\mathrm{N}_{\mathrm{i}}=1+\left(\left(1-\mathrm{p}_{\mathrm{o}}\right) /\left(\mathrm{p}_{\mathrm{o}}{ }^{*} \mathrm{OR} \mathrm{i}\right)\right.$ ), where $\mathrm{p}_{\mathrm{o}}$ is the prevalence of clinical proteinuria among individuals with no traits and $\mathrm{OR}_{\mathrm{i}}$ the adjusted odds-ratio for each individual trait or combination $\mathrm{i}$.

\section{Results}

Description of the 3,600 participants in the REDIA study

First step diabetes screening classified $12 \%$ of the participants as having known diabetes, $17.3 \%$ as screened positive, and $70.7 \%$ as screened negative. Dipstick proteinuria (1+ or plus) was present in $17.6 \%$ of the overall sample. Within each group defined by diabetes status at screening, participation in the clinic-based examination was not associated with baseline characteristics with few exceptions (Table 1): of individuals with known diabetes, participants and non-participants were comparable except for geographic area; of those with positive diabetes screening, participants were significantly older than non-participants and less likely to be men; this was also the case for those with negative diabetes screening. After adjustment for age, gender and geographic area, neither treated hypertension nor dipstick proteinuria was related to participation in the examination in any of the groups, but BMI was slightly higher in participants than non-participants among those screened negative. 
Proteinuria and renal function by diabetes status at the clinic-based examination

The percentage of clinical proteinuria was three times higher among known diabetic than non-diabetic participants and more than twice as high in new diabetic cases (Table 2). It increased with age, but did not significantly differ by gender. That of chronic renal insufficiency increased with age, but it was not related to diabetes. The percentage of participants with both clinical proteinuria and low eGFR $\mathrm{MDRD}_{\mathrm{M}}$ were $6.3 \%$ in participants with known diabetes, $3.6 \%$ in new diabetic cases, and $2.2 \%$ in those without diabetes.

\section{Prevalence estimate of chronic kidney disease}

Age-, gender-, and diabetes standardized prevalences of CKD stages are shown in Table III. To compare with other studies, both clinical proteinuria and albuminuria $(\geq$ $30 \mathrm{mg} / \mathrm{g}$ ) were used here to define stage 1-2 kidney damage; one or the other was present in $33 \%$ of the participants with known or new diabetes and in $14 \%$ of those without diabetes $(p<0.001)$. For all equations used to estimate eGFR, the standardised prevalences for all CKD stages were similar (Table 3), but the MDRD equation estimated lower levels of eGFR than the Cockcroft-Gault formula with different distributions across CKD stages.

\section{Association of CKD with the metabolic syndrome in non-diabetic participants}

Age-, gender- and area-adjusted odds ratios of clinical proteinuria significantly increased with the number of metabolic syndrome traits (Table 4). That of low eGFR $_{\mathrm{MDRD}}$ was higher with the presence of traits, but without a clear gradient. Further adjustment for smoking and physical activity did not alter any of these associations. Pattern of association did not differ significantly between men and women (data not shown). Each individual trait of the metabolic syndrome was associated with an increased odds-ratio of clinical proteinuria, although only statistically significant for elevated blood pressure and hypertriglyceridaemia (Table 5). The combinations of two traits most strongly associated with clinical proteinuria included hypertriglyceridaemia with either high blood pressure or hyperglycaemia (both $\mathrm{P}$ values $<0.10$ after Bonferroni correction). Those of three traits with the greatest odds-ratios all included high blood pressure and hypertriglyceridaemia; after correction, only that also including 
hyperglycaemia remained statistically significant ( $\mathrm{P}$ value $<0.01$ ). The odds-ratio for the triad including both lipid abnormalities and hyperglycaemia was also high, but involved very few individuals. Patterns of associations with low eGFR $\mathrm{MDRD}_{\mathrm{M}}$ were consistent with those for clinical proteinuria, but none of them were statistically significant after correction.

\section{Number of individuals needed to screen to detect one case of clinical proteinuria}

The number needed to screen to detect one case of clinical proteinuria among nondiabetic individuals with three or more traits was one fourth the necessary number for those with no traits. This number was even smaller among those with the triad including high blood pressure, high triglyceride levels, and hyperglycaemia, but it was slightly higher among non-diabetic individuals with hypertension alone. 


\section{Discussion}

This study shows a high prevalence of chronic kidney disease in the Reunion population, which was common in diabetic individuals, but surprisingly also in nondiabetics. In these individuals, the number of metabolic syndrome traits was strongly associated with the risk of clinical proteinuria and to a lesser extent with chronic renal insufficiency. These findings are original in that they identify combinations of the syndrome traits associated with particularly high risk for CKD in non-diabetic individuals. They also point out the potential efficiency of the syndrome for CKD targeted screening.

Comparison of our prevalence estimates with others is limited by differences between studies in their definition of CKD and in the characteristics of their populations. Nonetheless the estimates from the REDIA study of $24.6 \%$ for all CKD stages and $10.7 \%$ for chronic renal insufficiency (stages $3+$ ) were higher than those in the US population, $9.4 \%$ and $3.8 \%$, respectively, according to NHANES IV.[4] That of chronic renal insufficiency was also higher than the $2.5 \%$ estimated in Chinese adults, 35 to 74 years.[5] Urinary markers were measured only once in REDIA, whereas correction factors were applied in NHANES IV to take assumptions about albuminuria persistence into account, and our prevalence estimates for CKD stages 1 and 2 may be overestimated. On the other hand, albuminuria was not measured in all individuals, and some participants with proteinuria $<200 \mathrm{mg} / \mathrm{g}$ and no albuminuria measure may have been misclassified as not having kidney damage. Compared with other large populationbased surveys that used a single measure of urinary albumin, our percentage of subjects with either albuminuria ( $\geq 30 \mathrm{mg} / \mathrm{g}$ ) or clinical proteinuria - $14 \%$ in the non-diabetic participants from the REDIA study - was higher than that of albuminuria ( $\geq 20 \mathrm{mg} / \mathrm{l})$ in mainland France $-10 \%$ among the non-diabetic participants of similar age from the DESIR study.[23] It was also higher than the $8 \%$ albuminuria $(\geq 20 \mathrm{mg} / \mathrm{l})$ in the Groningen (the Netherlands) population aged 28 to 75 years from the PREVEND study[6] and about double that of albuminuria ( $\geq 30 \mathrm{mg} / \mathrm{g}$ creatinine) in Australia - 6\% in the non-diabetic participants aged 25 years and over from the AusDiab study. [7] In contrast, it was lower than the $21 \%$ albuminuria ( $\geq 30 \mathrm{mg} / \mathrm{g}$ creatinine) in non-diabetic Zuni Indians, estimated from Shah et al.[8] 
A high prevalence of CKD was expected in the Reunion population given its high prevalence of both diabetes $(17.5 \%)$ and $\operatorname{ESRD}(0.2 \%)$.[2,3] The frequency of clinical proteinuria and chronic renal insufficiency in non-diabetic individuals, however, shows that diabetes alone is not responsible for the huge progression of ESRD in this population. [1]

Very few population-based studies have examined the relation between the metabolic syndrome and $\mathrm{CKD}$. Our results are consistent with those from the crosssectional survey of Hoehner et al[24] among non-diabetic Native Americans, in whom the odds ratio for microalbuminuria was 2.3 for three or more traits versus none, except they observed different patterns of association for men and women, and we did not. Chen et al showed graded relations with the number of traits of the metabolic syndrome, which were stronger than in our study, for both microalbuminuria and chronic renal insufficiency in NHANES III, [17] and for chronic renal insufficiency in Chinese adults.[18] Both studies, however, included participants with diabetes and CKD risk in individuals with the metabolic syndrome may have reflected the presence of diabetes. In contrast, Kurella et al [19] and Ninomiya et al [20] observed a gradient similar in magnitude to ours for the risk of chronic renal insufficiency occurrence among US and Japanese non-diabetic adults, respectively. Tanaka et al[20] also showed a crosssectional relation with the number of traits of the syndrome, using a combined outcome of dipstick proteinuria $(\geq 1+)$ and reduced GFR to define CKD.

Central abdominal obesity is the phenotypic hallmark of the metabolic syndrome. Most available studies of association between renal risk and obesity, however, are based on BMI and they report inconsistent findings. [9-15,17-20] Iseki et al [12] observed a gradient of treated ESRD risk with elevated BMI in men, but not in women in a large cohort in Okinawa and Hsu et al[14] also found a strong gradient with treated ESRD in US adults from the Kaiser Health Check-up Cohort Study. On the other hand, we observed in NHANES II an increased risk of either treated ESRD or death with CKD limited to those with morbid obesity.[13] BMI was related to the incidence of low GFR in the Framingham Offsping study and among healthy men from the Physicians' Health study.[9,10] In the PREVEND study, central obesity was crosssectionally associated with both increased microalbuminuria and decreased creatinine clearance.[15] Finally, a high waist circumference was significantly associated with low 
GFR in US and Chinese adults, [17-19] but not with albuminuria in the former. [17,19] In the REDIA study as in a large cohort of Japanese adults [11], the association were stronger with proteinuria than with low GFR. In contrast, even mildly elevated blood pressure has been consistently associated with albuminuria,[6-8,17] and decreased GFR. $[4,5,9,11,17,19]$ The contribution of dyslipidaemia, typical of the metabolic syndrome, has been poorly studied at a population level. A greater risk of renal function decline was found in those with high triglyceride and low HDL-cholesterol levels in the ARIC study.[19,25] In NHANES III, high triglyceride levels were associated with microalbuminuria and both these lipid abnormalities with chronic renal insufficiency, [17] but neither was related to microalbuminuria in the Inter-tribal Heart Project.[24] In Chinese adults, low HDL-cholesterol, but not high triglycerides correlated with low GFR. [18] In REDIA, we found that a high triglyceride level was associated with clinical proteinuria, but more interestingly, that the clustering of either high triglyceride levels and blood pressure or high triglycerides and plasma glucose or the three of them conferred the strongest associations with both clinical proteinuria and low eGFR, with odds-ratios ranging from 4.2 to 13.3 for the former and from 2.4 to 5.3 for the latter. It is worth noting that abdominal obesity without these traits was not associated with a significant increase in proteinuria.

The cross-sectional design of this study does not allow a cause-and-effect relation to be established between the metabolic syndrome and CKD risk. Experimental studies in primates, however, show that renal changes occur early in the natural history of obesity-initiated metabolic syndrome. In prospective studies of rhesus monkeys, glomerular hypertrophy - the earliest evidence of structural change - precedes the onset of hyperglycaemia.[26] In humans, only one prospective study showed an association between the metabolic syndrome and an increased risk of incident chronic renal insufficiency in non-diabetic adults with eGFR $>60 \mathrm{ml} / \mathrm{mn} / 1.73 \mathrm{~m} 2$ at baseline.[19] Proteinuria was not measured in this study, however, and some individuals may have had baseline kidney damage with normal kidney function. There are many pathways by which metabolic syndrome might contribute to renal disease. Insulin resistance with compensatory hyperinsulinaemia, the fundamental abnormality of the metabolic syndrome, has been associated with low eGFR $(<60 \mathrm{ml} / \mathrm{mn} / 1.73 \mathrm{~m} 2)$ in nondiabetic US adults from NHANES III [27] and observed in the early course of non- 
diabetic nephropathies.[28] Altogether, these findings suggest that the syndrome may precede $\mathrm{CKD}$, but do not rule out the possibility that it is a marker and not a causative factor or even that the true association may be the reverse.

Three limitations of this study should be noted. First, although the source population was representative of Reunion, participants in each step of the study differed slightly from non-participants with respect to age and gender. Hypertension and dipstick proteinuria, however, were comparable after adjustment for age and gender. Standardising prevalence estimates thus reduced potential bias due to these nonparticipants. Second, as already mentioned, it is difficult to study ethnicity in the Reunion population. Although self-reported ethnicity was recorded, it was only used to correct the MDRD equation, to reduce the expected overestimation of low GFR values due to black ethnicity. We nonetheless cannot rule out the possibility that prevalence estimates of stages 3 and 4 based on eGFR $_{\mathrm{MDRD}}$, which are higher than those with eGFR $_{\mathrm{CG}}$, remain overestimated due to unvalidated use of this equation in this population. It is noteworthy, however, that relations with the metabolic syndrome did not change when eGFR $\mathrm{MDRD}_{\mathrm{M}}$ was not corrected for ethnicity. Finally, although Froissart et al [29] showed that the MDRD equation performed better than the Cockcroft-Gault formula in estimating GFR in French patients, the performance of these two equations in the general population is still debated, and it is difficult to determine which of our two prevalence estimates is more valid. Moreover, their poorer performance in healthy individuals, particularly women, may have led us to overestimate low GFR values in the non-diabetic participants. Indeed, the age-related associations of both clinical proteinuria and chronic renal insufficiency were more consistent among participants with either known or newly diagnosed diabetes than among those without diabetes.

The implications of these findings for clinical and public health are important. Current CKD guidelines recommend screening individuals with diabetes and hypertension for undetected kidney disease during routine clinical examination, because they benefit from aggressive blood pressure and glucose control to reduce renal risk.[21] This study clearly shows that case finding may be extended to individuals with the metabolic syndrome, particularly in those with a pattern of high triglyceride levels associated with elevated blood pressure or high fasting plama glucose. In non-diabetic populations at high renal risk, targeting these individuals would reduce the cost of such 
screening. It is not yet certain however that treatment of traits of the metabolic syndrome other than high blood pressure and diabetes will have an impact on CKD progression.

In conclusion, the metabolic syndrome may contribute to the early diagnosis of $\mathrm{CKD}$. These findings deserve to be confirmed in other populations where there may be different patterns of risk associated with the metabolic syndrome traits. Moreover, studies are warranted to assess whether early interventions in individuals with the metabolic syndrome and proteinuria is effective to prevent ESRD and cardiovascular diseases.

\section{Grant support}

This work was supported by grant DGS 980511 from the Direction des Hôpitaux, Paris, and grants from INSERM, the Conseil Général de la Réunion, and the Agence Régionale de l'Hospitalisation de la Réunion. 


\section{References}

1. Halimi S, Zmirou D, Benhamou PY, Balducci F, Zaoui P, Maghlaoua M, et al. Huge progression of diabetes prevalence and incidence among dialysed patients in mainland France and overseas French territories. A second national survey six years apart (UREMIDIAB 2 study). Diabetes Metab 1999; 25:507-12.

2. Macron-Noguès F, Vernay M, Ekong E, Salanave B, Revel M, Fender P, et al. The prevalence of end-stage kidney disease treated with renal dialysis in France in 2003. Am J Kidney Dis 2005;46:309-15.

3. Favier F, Jaussent I, Moullec NL, Debussche X, Boyer MC, Schwager JC, et al. The REDIA Study Group. Prevalence of Type 2 diabetes and central adiposity in La Reunion Island, the REDIA Study. Diabetes Res Clin Pract 2005;67:234-42.

4. Coresh J, Byrd-Holt D, Astor BC, Briggs JP, Eggers PW, Lacher DA, et al. Chronic Kidney Disease Awareness, Prevalence, and Trends among U.S. Adults, 1999 to 2000. J Am Soc Nephrol 2005;16:180-8.

5. Chen J, Wildman RP, Gu D, Kusek JW, Spruill M, Reynolds K,et al. Prevalence of decreased kidney function in Chinese adults aged 35 to 74 years. Kidney Int 2005;68:283745 .

6. Hillege HL, Janssen WMT, Bak AAA, Diercks GFH, Grobbee DE, Crijns HJGM, et al for the PREVEND Study Group. Microalbuminuria is common in a non-diabetic, nonhypertensive population, and an independant indicator of cardiovascular risk factors and cardiovascular morbidity. J Intern Med 2001;249:519-26.

7. Tapp RJ, Shaw JE, Zimmet PZ, Balkau B, Chadban SJ, Tonkin AM, et al. Albuminuria is evident in the early stages of diabetes onset: results from the Australian Diabetes, Obesity, and Lifestyle Study (AusDiab). Am J Kidney Dis 2004;44:792-8.

8. Shah VO, Scavini M, Stidley CA, Tentori F, Welty TK, MacCluer JW, et al. Epidemic of diabetic and nondiabetic renal disease among the Zuni Indians: the Zuni Kidney Project. J Am Soc Nephrol 2003;14:1320-29.

9. Fox CS, Larson MG, Leip EP, Culleton B, Wilson PW, Levy D. Predictors of new-onset kidney disease in a community-based population. JAMA 2004;291:844-50.

10. Gelber RP, Kurth T, Kausz AT, Manson JE, Buring JE, Levey AS, et al. Association between body mass index and CKD in apparently healthy men. Am J Kidney Dis 2005; 46:871-80.

11. Yamagata K, Ishida K, Sairenchi T, Takahashi H, Ohba S, Shiigai T, et al. Risk factors for chronic kidney disease in a community-based population: a 10-year follow-up study. Kidney Int 2007 ; 71:159-6 
12. Iseki $\mathrm{K}$, Ikemiya $\mathrm{Y}$, Kinjo $\mathrm{K}$, Inoue $\mathrm{T}$, Iseki $\mathrm{C}$, Takishita S. Body mass index and the risk of development of end-stage renal disease in a screened cohort. Kidney Int 2004;65:1870-6.

13. Stengel B, Tarver-Carr ME, Powe NR, Eberhardt MS, Brancati FL. Lifestyle behaviors, obesity, and the risk for chronic kidney disease in U.S. adults. Epidemiology 2003;14:47987.

14. Hsu CY, McCulloch CE, Iribarren C, Darbinian J, Go AS. Body mass index and risk for end-stage renal disease. Ann Intern Med 2006;144:21-8.

15. Pinto-Sietsma SJ, Navis G, Janssen WM, de Zeeuw D, Gans RO, de Jong PE; PREVEND Study Group. A central body fat distribution is related to renal function impairment, even in lean subjects. Am J Kidney Dis 2003;41:733-41.

16. Expert Panel on Detection, Evaluation, and Treatment of High Blood Cholesterol in Adults. Executive Summary of The Third Report of The National Cholesterol Education Program (NCEP) Expert Panel on Detection, Evaluation, And Treatment of High Blood Cholesterol In Adults (Adult Treatment Panel III). JAMA 2001;285:2486-97.

17. Chen J, Muntner P, Hamm LL, Jones DW, Batuman V, Fonseca V, et al. The metabolic syndrome and chronic kidney disease in U.S. adults. Ann Intern Med 2004;140:167-74.

18. Chen J, Gu D, Chen CS, Wu X, Hamm LL, Muntner P, et al. Association between the metabolic syndrome and chronic kidney disease in Chinese adults. Nephrol Dial Transplant 2007 Feb 1; [Epub ahead of print]

19. Kurella M, Lo JC, Chertow GM. Metabolic syndrome and the risk for chronic kidney disease among nondiabetic adults. J Am Soc Nephrol 2005;16:2134-40.

20. Ninomiya T, Kiyohara Y, Kubo M, Yonemoto K, Tanizaki Y, Doi Y, et al. Metabolic syndrome and CKD in a general Japanese population: the Hisayama Study. Am J Kidney Dis 2006;48:383-91.

21. National Kidney Foundation. K/DOQI Clinical practice guidelines for chronic kidney disease : Evaluation, Classification and Stratification. Am J Kidney Dis 2002;39:S1-S266 (suppl 1).

22. Eknoyan G, Hostetter T, Bakris GL, Hebert L, Levey AS, Parving HH, et al. Proteinuria and other markers of chronic kidney disease: a position statement of the national kidney foundation $(\mathrm{NKF})$ and the national institute of diabetes and digestive and kidney diseases (NIDDK). Am J Kidney Dis 2003;42:617-22. Review.

23. Balkau B, Eschwege E, Tichet J, Marre M. Proposed criteria for the diagnosis of diabetes: evidence from a French epidemiological study (D.E.S.I.R.).Diabetes Metab 1997;23:42834. 
24. Hoehner CM, Greenlund KJ, Rith-Najarian S, Casper ML, McClellan WM. Association of the insulin resistance syndrome and microalbuminuria among nondiabetic native Americans. The Inter-Tribal Heart Project. J Am Soc Nephrol 2002;13:1626-34.

25. Muntner P, Coresh J, Smith JC, Eckfeldt J, Klag MJ. Plasma lipids and risk of developing renal dysfunction: the atherosclerosis risk in communities study. Kidney Int 2000;58:293301.

26. Cusumano AM, Bodkin NL, Hansen BC, Iotti R, Owens J, Klotman PE, et al. Glomerular hypertrophy is associated with hyperinsulinemia and precedes overt diabetes in aging rhesus monkeys. Am J Kidney Dis 2002;40:1075-85.

27. Chen J, Muntner P, Hamm LL, Fonseca V, Batuman V, Whelton PK et al. Insulin resistance and risk of chronic kidney disease in nondiabetic US adults. J Am Soc Nephrol 2003;14:469-77.

28. Becker B, Kronenberg F, Kielstein JT, Haller H, Morath C, Ritz E, et al; MMKD Study Group. Renal insulin resistance syndrome, adiponectin and cardiovascular events in patients with kidney disease: the mild and moderate kidney disease study. J Am Soc Nephrol 2005;16:1091-8.

29. Froissart M, Rossert J, Jacquot C, Paillard M, Houillier P. Predictive performance of the modification of diet in renal disease and cockcroft-gault equations for estimating renal function. J Am Soc Nephrol 2005;16:763-73. 
Table I

Characteristics of the 3,600 participants in the REDIA study

\begin{tabular}{|c|c|c|c|c|c|c|c|c|c|}
\hline & \multicolumn{2}{|c|}{ Known Diabetes } & & \multicolumn{2}{|c|}{ Screened positive } & \multicolumn{4}{|c|}{ Screened negative } \\
\hline & Participants & Non-Participants & & Participants & Non-Participants & & Participants & Non-Participants & \\
\hline & $\mathrm{N}=\mathbf{3 1 2}$ & $\mathrm{N}=118$ & & $N=363$ & $N=261$ & & $N=275$ & $\mathrm{~N}=\mathbf{2 2 7 1}$ & \\
\hline & Mean \pm SD or $\%$ & Mean \pm SD or $\%$ & P-Value* & Mean \pm SD or $\%$ & Mean \pm SD or $\%$ & P-Value* & Mean \pm SD or $\%$ & Mean \pm SD or $\%$ & P-Value* \\
\hline \multicolumn{10}{|l|}{ Geographic area } \\
\hline Le Tampon & 33.7 & 18.6 & 0.003 & 32.8 & 46.3 & 0.002 & 23.3 & 25.3 & $\mathrm{~ns}$ \\
\hline St-Pierre & 29.8 & 28.8 & & 21.5 & 18.8 & & 32.4 & 34.1 & \\
\hline St-André & 36.5 & 52.5 & & 45.7 & 34.9 & & 44.3 & 40.6 & \\
\hline Age (years) & $54.4 \pm 9.2$ & $53.0 \pm 9.2$ & $\mathrm{~ns}$ & $51.2 \pm 10.4$ & $47.5 \pm 10.3$ & $<0.001$ & $45.9 \pm 10.4$ & $43.3 \pm 10.0$ & $<0.001$ \\
\hline Men & 42.3 & 41.5 & $\mathrm{~ns}$ & 39.4 & 53.3 & $<0.001$ & 38.2 & 44.4 & 0.05 \\
\hline BMI (kg/m2) & $27.3 \pm 4.6$ & $27.3 \pm 5.0$ & $\mathrm{~ns}$ & $28.0 \pm 5.2$ & $27.2 \pm 5.0$ & $\mathrm{~ns}$ & $25.9 \pm 4.9$ & $24.6 \pm 4.3$ & $<0.001$ \\
\hline Treated Hypertension & 42.1 & 44.9 & $\mathrm{~ns}$ & 25.6 & 15.3 & $\mathrm{~ns}$ & 13.1 & 9.2 & $\mathrm{~ns}$ \\
\hline \multicolumn{10}{|l|}{ Dipstick proteinuria } \\
\hline $1+$ & 7.8 & 12.9 & $\mathrm{~ns}$ & 10.3 & 11.3 & $\mathrm{~ns}$ & 11.3 & 11.9 & $\mathrm{~ns}$ \\
\hline $2+$ & 8.5 & 11.2 & & 5.9 & 6.2 & & 2.6 & 3.4 & \\
\hline $3+$ & 8.8 & 7.8 & & 2.2 & 0.4 & & 0.4 & 0.8 & \\
\hline
\end{tabular}

1 
Table II

Percentages of clinical proteinuria and chronic renal insufficiency by diabetes status at the clinic-based examination

\begin{tabular}{|c|c|c|c|c|c|c|c|c|c|c|c|}
\hline & \multicolumn{3}{|c|}{$\begin{array}{c}\text { Sample size } \\
\text { at the clinic-based examination }\end{array}$} & \multicolumn{4}{|c|}{ Proteinuria $>200 \mathrm{mg} / \mathrm{g}$ creatinine } & \multicolumn{4}{|c|}{$\begin{array}{c}\text { Chronic renal insufficiency } \\
\text { eGFR }_{\mathrm{MDRD}}<60 \mathrm{ml} / \mathrm{mn} / 1.73 \mathrm{~m}^{2}\end{array}$} \\
\hline & Known & New & & Known & New & & & Known & New & & \\
\hline & Diabetes & Diabetes & No diabetes & Diabetes & Diabetes & No diabetes & & Diabetes & Diabetes & No diabetes & \\
\hline & $\mathrm{n}$ & $\mathrm{n}$ & $\mathrm{n}$ & $\%$ & $\%$ & $\%$ & $P$ value ${ }^{a}$ & $\%$ & $\%$ & $\%$ & P value $^{\mathrm{a}}$ \\
\hline$\overline{\text { Men }}$ & 130 & 50 & 196 & 23.1 & 14.0 & 6.1 & $<0.0001$ & 9.2 & 8.0 & 9.7 & ns \\
\hline Women & 170 & 61 & 313 & 30.0 & 24.6 & 10.2 & $<0.0001$ & 15.3 & 18.0 & 13.7 & ns \\
\hline \multicolumn{12}{|l|}{ Age } \\
\hline $30-39$ & 22 & 14 & 145 & 18.2 & 14.3 & 5.5 & - & 4.6 & 0 & 9.7 & - \\
\hline $40-49$ & 77 & 34 & 154 & 16.9 & 20.6 & 8.4 & $<0.10$ & 3.9 & 8.8 & 9.7 & $\mathrm{~ns}$ \\
\hline $50-59$ & 104 & 30 & 122 & 30.8 & 20.0 & 7.4 & $<0.0001$ & 12.5 & 13.3 & 18.0 & ns \\
\hline$\geq 60$ & 97 & 33 & 88 & 33.0 & 21.2 & 15.9 & $<0.05$ & 21.7 & 24.2 & 12.5 & $\mathrm{~ns}$ \\
\hline Overall & 300 & 111 & 509 & 27.0 & 19.8 & 8.6 & $<0.0001$ & 12.7 & 13.5 & 12.2 & $\mathrm{~ns}$ \\
\hline
\end{tabular}

${ }^{a} p$ value of the comparison between the three groups defined by diabetic status

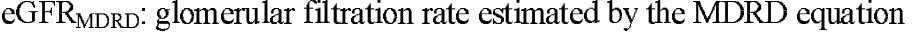


Table III

Standardised prevalence* of chronic kidney disease (CKD) in the Reunion Island

\begin{tabular}{cccc} 
& \multicolumn{1}{c}{ CKD Classification } & eGFR $_{\text {MDRD }}$ & eGFR $_{\mathrm{CG}}$ \\
Stage & Description & $\%[95 \% \mathrm{CI}]$ & $\%[95 \% \mathrm{CI}]$ \\
\hline 1 & Kidney damage $\uparrow$ and eGFR $\geq 90$ & $5.8[4.3-7.3]$ & $9.9[7.9-11.8]$ \\
2 & Kidney damage and eGFR 60-89 & $8.0[6.5-9.5]$ & $7.4[5.4-9.3]$ \\
3 & eGFR 30-59 & $10.3[8.4-12.3]$ & $6.6[5.1-8.3]$ \\
$4-5$ & eGFR $<30$ & $0.4[0-0.8]$ & $0.5[0-1.2]$ \\
All stages & & $24.6[21.7-27.4]$ & $24.5[21.2-27.8]$
\end{tabular}

*Direct standardisation method using the age and gender distribution of Reunion Island from 1999 Census data as well as diabetes prevalence as estimated from the REDIA study (see methods).

$\uparrow$ Kidney damage defined as either albuminuria $(\geq 30 \mathrm{mg} / \mathrm{g}$ creatinine $)$ or clinical proteinuria $(>200 \mathrm{mg} / \mathrm{g}$ creatinine); $\mathrm{eGFR}_{\mathrm{MDRD}}$, glomerular filtration rate in $\mathrm{ml} / \mathrm{mn} / 1.73 \mathrm{~m}^{2}$ calculated with the $\mathrm{MDRD}$ equation; eGFR $_{\mathrm{CG}}$, GFR calculated with the Cockcroft-Gault formula and standardised for body surface area. 


\section{Table IV}

Odds ratio of clinical proteinuria and chronic renal insufficiency associated with the metabolic syndrome among participants without diabetes and number (Ni) needed to screen to detect one case

\begin{tabular}{|c|c|c|c|c|c|c|}
\hline & \multicolumn{3}{|c|}{$\begin{array}{l}\text { Clinical proteinuria } \\
>200 \mathrm{mg} / \mathrm{g} \text { creatinine }\end{array}$} & \multicolumn{3}{|c|}{$\begin{array}{c}\text { Chronic renal insufficiency } \\
\text { eGFR }_{\text {MDRD }}<60 \mathrm{ml} / \mathrm{mn} / 1.73 \mathrm{~m}^{2}\end{array}$} \\
\hline & $\%$ & OR [IC 95\%] & $\mathrm{Ni}$ & $\%$ & OR [IC 95\%] & $\mathrm{Ni}$ \\
\hline \multicolumn{7}{|c|}{ Number of metabolic } \\
\hline \multicolumn{7}{|c|}{ syndrome traits } \\
\hline 0 & 3.7 & 1 & 27 & 8.3 & 1 & 12 \\
\hline 1 & 5.3 & $1.5[0.4-5.2]$ & 18 & 14.5 & $1.9[0.8-4.5]$ & 7 \\
\hline 2 & 8.4 & $2.0[0.6-6.6]$ & 14 & 8.4 & $0.9[0.4-2.4]$ & 13 \\
\hline $3+$ & 16.1 & $4.1[1.3-12.8]$ & 7 & 17.7 & $2.2[0.9-5.1]$ & 6 \\
\hline
\end{tabular}

${ }^{a} \mathrm{OR}$ adjusted for age, sex and geographic area. 
Table V

Odds ratios of clinical proteinuria and chronic renal insufficiency for each trait and grouping of two or three traits of the metabolic syndrome among participants without diabetes and number (Ni) of individuals with the abnormality needed to screen to detect one case
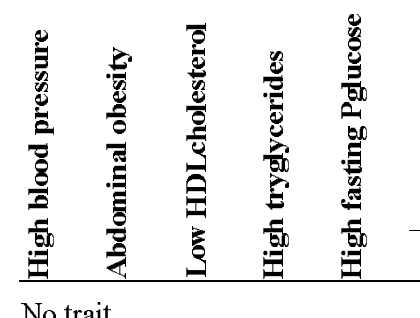

\begin{tabular}{|c|c|c|c|c|c|}
\hline \multicolumn{3}{|c|}{$\begin{array}{l}\text { Clinical proteinuria } \\
>200 \mathrm{mg} / \mathrm{g} \text { creatinine }\end{array}$} & \multicolumn{3}{|c|}{$\begin{array}{c}\text { Chronic renal insufficiency eGFR } \\
\qquad 60 \mathrm{ml} / \mathrm{mn} / 1.73 \mathrm{~m}^{2}\end{array}$} \\
\hline$\%$ & $\mathrm{OR}^{\mathrm{a}}[95 \% \mathrm{IC}]$ & $\mathbf{N i}$ & $\%$ & $\mathrm{OR}^{\mathrm{a}}[95 \% \mathrm{IC}]$ & $\mathbf{N i}$ \\
\hline 3.7 & $\operatorname{Ref}$ & 27 & 8.3 & Ref & 12 \\
\hline
\end{tabular}

Individual traits

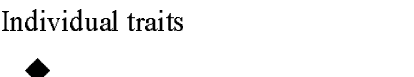

$\begin{array}{lllllll}11.7 & 2.8[1.0-8.5] & 10 & 12.5 & 1.5[0.7-3.3] & 8 \\ & 12.8 & 2.9[0.9-9.2] & 10 & 15.8 & 1.8[0.8-4.1] & 7 \\ & 10.1 & 2.8[0.9-8.7] & 10 & 13.8 & 1.8[0.8-4.0] & 7 \\ \bullet \quad & 13.2 & 3.6[1.1-12.4] & 8 & 16.5 & 1.8[0.7-4.6] & 7 \\ & 10.6 & 2.7[0.7-10.7] & 11 & 16.7 & 1.7[0.6-4.6] & 7\end{array}$

Combinations of two traits

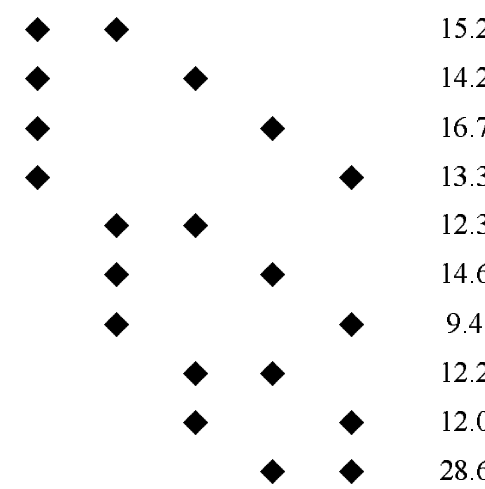

15.2
14.2
16.7
13.3
12.3
14.6
9.4
12.2
12.0
28.6

$3.1[1.0-10.3] \quad 9$

16.6

$2.0[0.8-4.8]$

$1.7[0.7-4.2]$

$2.4[0.9-6.1]$

$4.9[1.4-17.3]$

15.0

$1.4[0.4-4.4]$

3.1 [0.7-13.2]

19.7

2.0[0.8-5.4]

$2.3[0.8-6.6]$

$1.1[0.3-4.2]$

$1.7[0.6-5.0]$

$2.4[0.7-8.3]$

4.2 [0. 8-22.1]

$2.4[0.7-8.3]$

$12.2[2.1-70.1] \quad 3 \quad 28.6$

$3.7[0.9-15.8] \quad 4$

Combinations of three traits

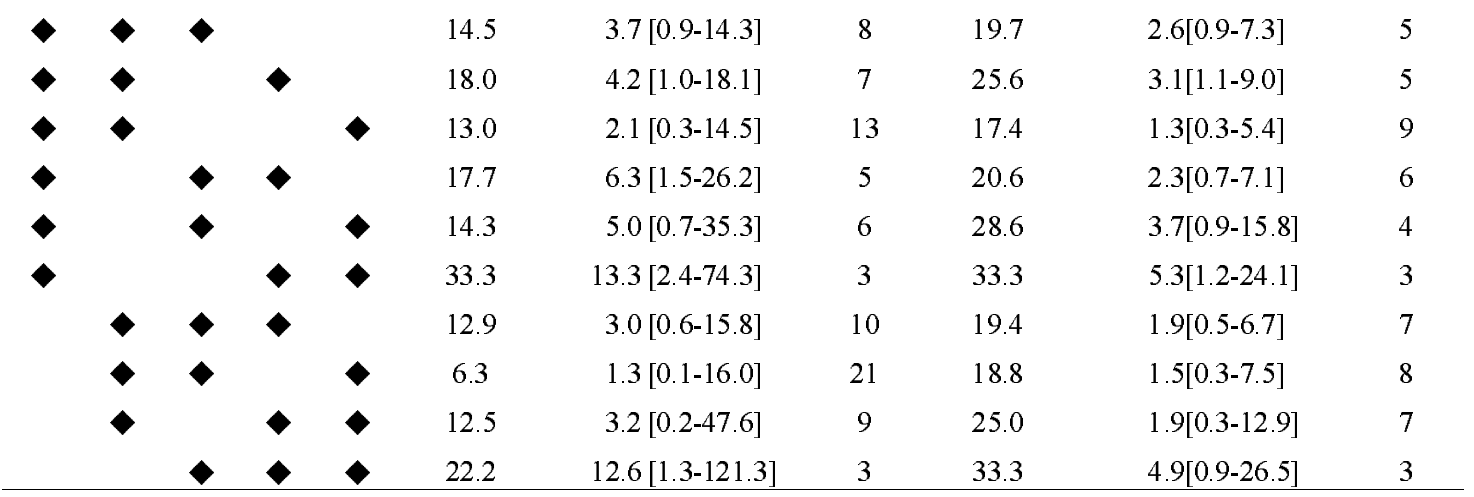

${ }^{\mathrm{a}} \mathrm{OR}$ adjusted for age, sex and geographic area. 
Figure - REDIA Study Design

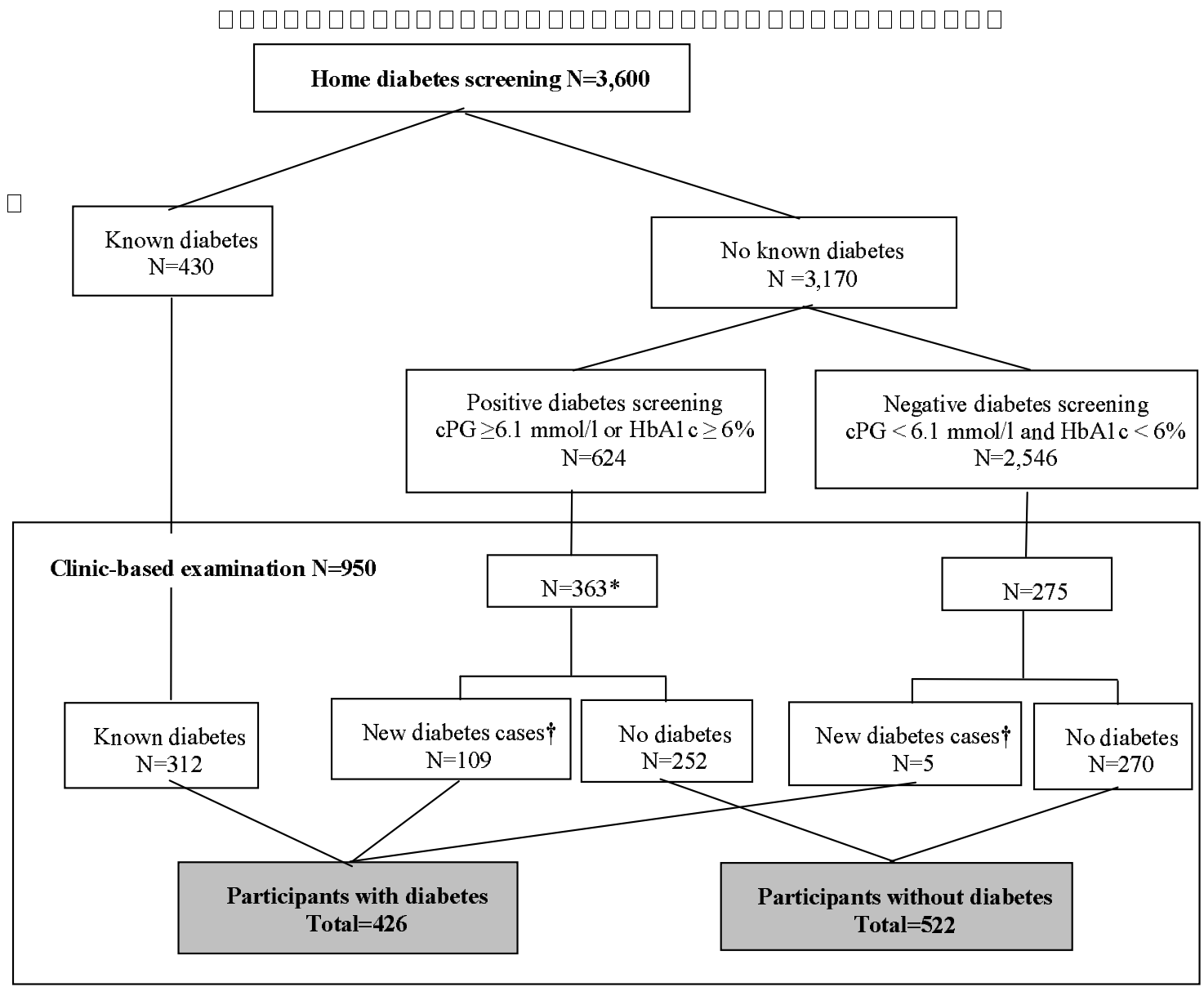

cPG : capillary plasma glucose

* includes two individuals with unknown diabetes status after the clinic-based examination

† New diabetes cases defined as either capillary blood glucose or 2-hour plasma glucose level $\geq 200 \mathrm{mg} / \mathrm{dl}(11.1$

$\mathrm{mmol} / \mathrm{l}$ ), or 2 -hour plasma glucose level $<200 \mathrm{mg} / \mathrm{dl}$, but fasting plasma and capillary blood glucose levels $\geq 126 \mathrm{mg} / \mathrm{dl}$

$(7.0 \mathrm{mmol} / \mathrm{l})$ 